\title{
A Review of Researches on Accounting in China Brought by Artificial Intelligence*
}

\author{
Youyun Wen \\ South China Business College Guangdong University of Foreign Studies \\ Guangzhou, China
}

\begin{abstract}
In recent years, with the innovation and development of science and technology, the application of artificial intelligence technology in accounting field has become more and more extensive and in-depth. The integration of artificial intelligence and accounting is both an opportunity and a challenge. This paper combs the research literatures in the field of accounting brought by artificial intelligence, gets to know the basic situation of the research literatures, analyzes the application status, influence and coping strategies of artificial intelligence in accounting field, points out the limitations of existing research, and provides reference recommendations for the future research trend.
\end{abstract} review

Keywords-artificial intelligence; accounting; literature

\section{INTRODUCTION}

China's researches on artificial intelligence began in 1978 with scholar Chen Bu's "Philosophy Discussion on Artificial Intelligence Problems". Later, Chinese scholars made discussions on several problems such as, artificial intelligence and human intelligence, the philosophical problems artificial intelligence, technical research on artificial intelligence, and the application of artificial intelligence in various fields. Artificial intelligence accounting research originated recently. Miklos A (1989) pointed out in his monograph that artificial intelligence can be applied to the construction of an expert system for accounting and auditing. Deloitte Touche Tohmatsu and Smacc applied artificial intelligence in accounting and made breakthroughs in artificial intelligence based accounting. In March 2017, Deloitte Touche Tohmatsu, one of the world's four largest accounting firms, announced that it will join hands with Ki-ra System to apply artificial intelligence into accounting, taxation and auditing. When Deloitte's financial robot video appeared on the network, an uproar raised among accounting staffs. Meanwhile, Smacc's artificial intelligence accounting software can convert customer invoices into machine reading mode. This also shows that in the future, the accounting industry will face unprecedented challenges in the wave of artificial intelligence. To this end, the "artificial intelligence and accounting / financial management / audit / taxation" research literatures published in China's current publications were taken as the research

*Fund: This paper is a phased result of Guangdong Provincial Department of Education's 2018 School-Enterprise Collaborative Education Project: "Artificial Intelligence + Management Accounting" Young and middle aged teachers' teaching ability improvement (PROJ1006413551163805696). objects to observe the structural distribution and change in the points of research on artificial intelligence in the field of accounting in China by setting corresponding observation points. Further, this paper describes and analyzes the research ideas and their evolution trace.

\section{GENERAL DESCRIPTION OF THE RESEARCH LITERATURES}

\section{A. Basic Information on the Temporal Distribution of Research Literatures}

In this research, the author searched "人工智能 (artificial intelligence)" and "会计 (accounting)"/ "审计 (audit)"/ "财务管 理 (financial management)"/ "税务 (taxation)" under the search item of "title" on CNKI and conducted advanced searches on "all journals" up to Aug., 2019; totally, 390 articles were collected. The specific temporal distribution is shown in "Table I":

TABLE I. TEMPORAL DISTRIBUTION OF RESEARCH LITERATURES

\begin{tabular}{|c|c|c|c|c|c|}
\hline \multirow[t]{2}{*}{ Year } & \multicolumn{5}{|c|}{ Search item } \\
\hline & $\begin{array}{l}\text { "人工智能 } \\
\text { (artificial } \\
\text { intelligence)" } \\
\text { and "会 计 } \\
\text { (accounting)" }\end{array}$ & $\begin{array}{l}\text { "人工智 能 } \\
\text { (artificial } \\
\text { intelligence)" } \\
\text { and "审 计 } \\
\text { (audit)" }\end{array}$ & $\begin{array}{l}\text { "人工智能 } \\
\text { (artificial } \\
\text { intelligence)" } \\
\text { and "财务管 } \\
\text { 理 (financial } \\
\text { management)" }\end{array}$ & $\begin{array}{l}\text { "人工智 能 } \\
\text { (artificial } \\
\text { intelligence)" } \\
\text { and "税 务 } \\
\text { (taxation)" }\end{array}$ & Total \\
\hline 1997 & 1 & & & & 1 \\
\hline 2003 & & & 1 & & 1 \\
\hline 2005 & 1 & & & & 1 \\
\hline 2009 & 1 & & 1 & & 2 \\
\hline 2010 & & 1 & & & 1 \\
\hline 2012 & & 1 & & & 1 \\
\hline 2016 & 1 & 2 & & & 3 \\
\hline 2017 & 26 & 7 & 6 & & 39 \\
\hline 2018 & 124 & 15 & 16 & 4 & 159 \\
\hline $\begin{array}{l}2019.1- \\
8\end{array}$ & 153 & 14 & 14 & 1 & 182 \\
\hline Total & 307 & 40 & 38 & 5 & 390 \\
\hline
\end{tabular}

As can be seen from "Table I", the researches on artificial intelligence in the field of accounting were mainly made in recent two years, reaching 159 articles in 2018 and 180 articles in January-August 2019. This is mainly because in March 2017, Deloitte Touche Tohmatsu, one of the world's four largest accounting firms, announced that it will join 
hands with Ki-ra System to apply artificial intelligence into accounting, taxation and auditing. KPMG also announced the introduction of IBM watson cognitive technology. The release of that news quickly led to researches on artificial intelligence in the field of accounting. From the research themes, the main research focuses on artificial intelligence in accounting; there have already been 307 articles about researches in this aspect. There are also certain researches on artificial intelligence in audit and that in finance, with 40 and 38 articles respectively. There are relatively few researches on artificial intelligence in taxation, with only five articles and mainly about the basic situation of applying artificial intelligence in tax management.

\section{B. Basic Information on the Publications That Published with Such Research Literatures}

Among the existing research literatures, only 15 articles were published in core journals, and were mainly published in publications such as the Finance \& Accounting, the Communication of Finance and Accounting, the Finance and Accounting Monthly and the Friends of Accounting; the remained 375 articles were published in general publications. This shows that although the researches on artificial intelligence in accounting have made some breakthroughs in the quantity in recent years, the breadth and depth of the research are not enough. The published academic journals lack high theoretical and authoritative natures and fail to reach a high cognition degree in the fields of accounting and audit in China.

\section{Basic Information of the Topics of Such Research Literatures}

According to the contents of the existing research literatures, the current research topics about artificial intelligence in accounting field ${ }^{1}$ are mainly concentrated in four aspects: the application of artificial intelligence in accounting field, the impact of artificial intelligence on the accounting field, the transformation from financial accounting to management accounting through artificial intelligence, and the cultivation of accounting talents in the context of artificial intelligence.

\section{REVIEW AND ANALYSIS OF THE RESEARCH CONTENTS}

\section{A. Researches on the Application of Artificial Intelligence in Accounting Field}

The research on artificial intelligence in the field of accounting in China began with a scholar who put forward to use artificial intelligence technology to design an intelligent decision supporting system. Feng Jing (1999) proposed that the intelligent financial decision supporting system is a combination of traditional financial decision supporting system and artificial intelligence, and is a decision aid. It helps decision makers make decision analysis in complex context to determine a best solution to a problem. Liang Ronghua and Shi Jijian (2001) focused on the financial knowledge representation and financial reasoning

\footnotetext{
The accounting field mentioned in the text includes accounting, auditing, finance, and taxation and the like aspects.
}

mechanism used in implementation of knowledge base system of the financial decision supporting system, and expounded the structural framework and implementation of the financial decision supporting system. $\mathrm{Xu}$ Yingjie, $\mathrm{Gu}$ Linlin, and Deng Jinpeng (2005) proposed the idea of identifying false accounting information in an intelligent way, and initially established a module system for the system. Huang Liaolong (2009) believed that artificial intelligence can be applied in expert system, pattern recognition, resource planning and configuration, intelligent financial management information sharing system, and artificial neural network models.

Deloitte Touche Tohmatsu announced a partnership with Kira Systems to introduce artificial intelligence into accounting work; KPMG jointed hand with IBM to use Watson's cognitive computing technology to conduct accounting and audit works; PwC also launched robotic automation solution. In July 2016, the "Kidney Bean Accounting" independently developed by China was officially put into trial online, which officially started the application of artificial intelligence in accounting work. According to the view of many scholars, the current application of artificial intelligence in accounting industry can be roughly divided into accounting, auditing and financial management. In terms of accounting, Lei Liping (2017) believed that the current accounting industry, including accounting firms, business units and government agencies, were widely applying computerized software and simple artificial intelligence tools for processing daily accounting such as filling voucher, bookkeeping, reconciliation, checkout, etc. Wang Jiacan and Su Yang (2017) found that many large enterprises are currently trying to use the "artificial intelligence + accounting big data" model for accounting, namely the intelligent use of enterprise accounting data. This way is in line with the requirement of large enterprise groups and multinational companies to quickly use the accounting data of each branch across regions. In terms of auditing, Bill et al. (2017) believed that the widest application of artificial intelligence in auditing is to process massive data and artificial intelligence can help quickly find the key data needed by auditors from a large amount of data. In terms of financial management, Wang Jing (2017) put forward the application of artificial intelligence in college financial services, and expounded the application design of the first financial intelligent service robot (including face-to-face interactive intelligent service robot and PC-based mobile-side virtual robot) in colleges and universities nationwide. Zhang Yiyou (2018) believed that artificial intelligence had been widely applied in the integration of online reimbursement system and management information system for electronic invoices and accounting electronic files.

With the development of society and science and technology, the application field of artificial intelligence in accounting work will be further expanded. Chen Hong (2018) believed that artificial intelligence will be widely used in economic prospect forecasting, participation in accounting management decision-making and planning, and asset valuation and forecasting. Sun Hongxi (2018) believed that 
intelligence can provide information, build models, and simulate future environment to help management accountant accomplish tasks, but cannot completely replace management accountant in making management decisions. Therefore, both financial accountant and management accountant have features that cannot be replaced by financial robots (Zhou Yaoling et al., 2018). It is also difficult for artificial intelligence to achieve effective audit communication and observation. Artificial intelligence is lack of audit judgment ability and is difficult to guarantee information security. Therefore, artificial intelligence cannot completely replace audit work (Wu Weixia, 2018).

2) Research on the in-depth impact of artificial intelligence on accounting field

Artificial intelligence has spawned a new accounting model. With the help of artificial intelligence technology, the accounting data has achieved a qualitative leap and the accounting model has changed. This makes the accounting process more realistic, reliable and timely; the accounting report model becomes more diverse, relevant and effective; artificial intelligence also reshapes accounting concepts, reconstructs the structure of accounting disciplines, and urgently needs complex innovative talents (Wang Jiacan et al., 2017). Artificial intelligence has also spawned a new audit operation mode, namely the "artificial intelligence + audit" operation mode. In the initial application stage, this mode has automized partial audit work. In the mature application stage, this mode will fully automatic audit work (Liu Jie et al., 2019).

Artificial intelligence reduces the demand for traditional accountants, and also brings new job opportunity and functional needs. Most scholars such as Bai Yuanyuan (2018) and Chen Minjie (2018) put forward that in this way, people have more time and energy to engage in works of management accountant such as decision forecast, evaluation control, strategies, and risk management; Li Xiujuan, Chen Yuanyi (2018) and et al proposed that with the continuous development of financial information system, the development, application and maintenance of financial robots required a group of compound talents who knew about financial knowledge and were proficient in computer programming and maintenance. Therefore, the future functions of accountant will be reflected in the development and maintenance of artificial intelligence. Chen Minjie (2018) put forward that some new forms of fraud and new types of errors might appear in the context of artificial intelligence. It is needed to research some new audit methods to carry out the audit work in a more targeted and effective manner. And with the deepening of artificial intelligence application, accountants' job titles and functions will be constantly changing. Liu Jie et al (2019) thought that in early application of artificial intelligence, those engaging in basic audit work will face the risk of unemployment, but their professional audit judgment and issuing audit report will be temporarily retained; In the mid-term application of artificial intelligence, the audit industry will raise many new positions or occupations, such as audit data analysts, to meet the challenges brought by artificial intelligence. In the peak period of application of artificial intelligence, multi-domain 
artificial intelligence technologies will be integrated and applied. The audit industry may only need those who can make auditing rules and those who can engage in development of integrated application of multiple artificial intelligence technologies. Most of the traditional audit posts will disappear.

\section{Research on the Transformation from Financial Accounting to Management Accounting}

With the development and breakthrough of artificial intelligence technology, the trend of transformation from empirical accounting to value accounting becomes more and more obvious. The integration of financial accounting and management accounting and the transformation from financial accounting to management accounting have become a general trend. For this reason, 41 scholars took "the transformation (integration) from financial accounting to management accounting" as the theme and discussed the differences between financial accounting and management accounting, the meaning and strategy of the transformation (integration).

1) Research on the necessity and practical significance of the transformation (integration)

$\mathrm{Xu}$ Anguo (2018) believed that with the arrival of information age, the traditional financial accounting methods could not meet the requirements of enterprise development any more, management accounting thinking was more suitable for artificial intelligence requirements, and the transformation of corporate from financial accounting to management accounting was also needed for strategic management of an enterprise. Gao Lianshu (2018) also proposed that the transformation from financial accounting to management accounting conformed to the macro-policy requirements of China, and also adapted to the changes in work functions brought by technical factors, and meet the market demand for talents.

$\mathrm{Xu}$ Qian (2018) believed that the transformation from financial accounting to management accounting can achieve data homology, promote fine management of enterprises, improve efficiency, save costs, strengthen internal control, control risks, and create new value for enterprises. Zhu Ning (2019) thought that the transformation from financial accounting to management accounting is conducive to the overall improvement of accounting information quality, playing the management role of accountant, establishing the relationship between corporate strategy and financial performance, and increasing the efficiency and quality of enterprise management.

2) Research on problems existing in the transformation (integration)

Xu Anguo (2018), Liu Lei (2018), Wang Liwei (2018), Zheng Zhong (2018) and other scholars discussed the problems encountered in the transformation. The main points of view are summarized in four aspects: first, the management of company pays insufficient attention to the financial management of the enterprise, lacks understanding of the role of artificial intelligence in accounting, and lacks understanding of the accounting function; second, the knowledge system of enterprise accountants is outdated, their knowledge of information technology and management is not enough and their ability and quality can not meet the requirement for management accountant; third, there is not a sound internal management mechanism and financial information system in enterprise so that management accountant cannot function well. Fourth, the finance and businesses of different department of the enterprise lack cooperation and were not effectively integrated so that the function of management accountant is limited.

3) Research on strategies for the transformation (integration)

41 scholars all put forward some suggestions or strategies for the transformation (integration) from financial accounting to management accounting. The author combed and their main point of views, and summarized 10 major coping strategies. ("Table III").

TABLE III. STATISTICS ON STRATEGIES FOR THE TRANSFORMATION FROM FINANCIAL ACCOUNTING TO MANAGEMENT ACCOUNTING

\begin{tabular}{|l|l|}
\hline \multicolumn{1}{|c|}{ Main point of view } & Frequency \\
\hline $\begin{array}{l}\text { 1. Conduct training or self-study to improve the } \\
\text { quality and ability of financial staffs, including } \\
\text { business, management, leadership and } \\
\text { communication skills. }\end{array}$ & 29 \\
\hline $\begin{array}{l}\text { 2. Strengthen information construction and } \\
\text { effectively use science and technology }\end{array}$ & 28 \\
\hline $\begin{array}{l}\text { 3. Change the traditional financial management } \\
\text { concepts and financial positioning, improve } \\
\text { management accounting awareness, and pay } \\
\text { attention to management accounting work }\end{array}$ & 19 \\
\hline $\begin{array}{l}\text { 4. Improve management model and establish an } \\
\text { effective financial management system }\end{array}$ & 18 \\
\hline $\begin{array}{l}\text { 5. Consolidate resources, achieve financial } \\
\text { integration and data interoperability, and } \\
\text { establish a financial sharing center }\end{array}$ & 15 \\
\hline $\begin{array}{l}\text { 6. Redistribute the structures of financial } \\
\text { organization and financial staffing }\end{array}$ & 12 \\
\hline $\begin{array}{l}\text { 7. For small and medium-sized enterprises with } \\
\text { weak information foundation, they can outsource } \\
\text { the financial basic accounting function to } \\
\text { external financial sharing service center. }\end{array}$ & 2 \\
\hline 8. Emphasize on accounting theory innovation & 2 \\
\hline $\begin{array}{l}\text { 9. Optimize financial information processing } \\
\text { flow by virtue of AI }\end{array}$ & 1 \\
\hline $\begin{array}{l}\text { 10. Optimize policy implementation at the } \\
\text { national level and improve the technology } \\
\text { application mechanism }\end{array}$ & 1 \\
\hline
\end{tabular}

D. Research on the Cultivation of Professional Accounting Personnel in the Context of Artificial Intelligence

The cultivation of accounting personnel is mainly conducted in colleges and universities. At present, the accounting course system of colleges and universities mainly includes financial accounting, supplemented by management accounting. This means that the talents cultivated by colleges and universities mainly have accounting function. However with the emergence of artificial intelligence, it is needed to change the function of accountant to the function of value creation. This means that the objectives, curriculum system and teaching content, teaching methods and means, training mode and assessment methods of accounting education in colleges and universities need to be changed. 
financial accounting integrating economics, philosophy, and management. The curriculum provided should not be merely limited to the integration of artificial intelligence and accounting. Peng Chafang (2019) proposed to reduce the class hours of some accounting courses, appropriately reduce the difficulty coefficient, and establish a group of hierarchical courses for management accounting. Shang Sizheng, Chen Jianyun and et al (2018) thought that financial accounting curriculum has more important position than that in the original time, but the financial accounting curriculum here refers to a financial conceptual framework. Wang Jiacan and Zhang Zixin believed that accounting students need to cleverly and proficiently use artificial intelligence, while Shang Sizheng and Huang Liucang believed that accounting students also need to learn computer programming technology to achieve cooperative development together with computer professionals. Liu Kailin (2019) also proposed that universities should combine artificial intelligence technology to additionally set up courses such as advanced Excel, algorithms, data acquisition and analysis. Lv Nan (2019) proposed a more specific curriculum requirement, namely to adjust the proportion of basic accounting courses, increase the proportion of management accounting curriculum systems such as corporate strategy, risk management, budgeting, performance measurement, and decision analysis, and additionally set up data processing and analysis, basic programming teaching and other courses, at the same time build in the basic teaching of big data and cloud computing methods. Peng Qifa and et al (2019) also mentioned that getting artificial intelligence technology introduced into accounting discipline construction and accounting vocational education is to prevent the overreliance on technical risks brought by artificial intelligence.

In terms of teaching methods, means and assessment methods, Ge Xin and Zuo Zhanwei (2016) believed that school-enterprise cooperation and work-study combination can help the cultivation of management accounting talents. Liu Kailin (2019) advocated student-based education, as well as "doing before learning", "learning before teaching" and "teaching by learning" to eventually realize the goal of "teaching by not teaching"; he also proposed to deepen the integration of industry and education. Colleges and universities should link with enterprise one by one and hire corporate elites to carry out skill training for students. Chen Xiaoqin (2019) put forward to take students competencies as the major evaluation content and make a comprehensive evaluation on students from multiple dimensions such as expertise, professional skills, professional ethics, communication ability and execution ability. The written test, report submission, and defense combined form can be used to give full play to the incentive role of the test.

In terms of teachers, school can encourage teachers to actively take part in information-based teaching, AI development and the like lectures and trainings in holiday (Wang Shijing, 2019), or invite external accounting experts and scholars such as senior executives of enterprise, Internet pioneers, and so on to gives lectures and training on the latest knowledge of the industry to teachers and students (Chen Xiaoqin, 2019). School can also invite AI industrial talents to universities should not only provide the AI and accounting integrated courses, but also offer general theory courses of been reached in the integration of accounting courses and artificial intelligence courses. It is necessary to learn the AI and accounting integrated courses; but there are still some disputes in the breadth and depth of the integration. Shang Sizheng, Chen Jianyun and et al (2018) believed that applied 
serve as visiting professors in the school to change the thinking of students (Dong Shaoxiao, 2019).

\section{CONCLUSION}

China's research on artificial intelligence in accounting field has achieved certain results. Its popularity is the result of the fact that in recent two years, China's academic and practical circles generally pay attention to the impact of artificial intelligence on accounting field, including the impact on accounting industry, accounting work and accounting education. But the research is still limited to qualitative analysis and lack of quantitative scientific judgment. Moreover, few of the existing researches are published on core journals, and the research results lack depth and authority.

There is no doubt that artificial intelligence has positive impact on accounting field; and a consensus that basic accounting and audit work will be replaced by artificial intelligence has been reached. The transformation from financial accounting to management accounting has become an inevitable trend. However, with the deepening of artificial intelligence technology, further researches are needed as for how much the accounting work is replaced by artificial intelligence, and what the future accounting positions and accounting functions will be.

The development of artificial intelligence drives the reconstruction of accounting discipline. Accounting discipline must be integrated with other disciplines to cultivate composite accounting talents. But further researches are still needed as for the targeted disciplines of the integration, the integration depth, and the post-graduate talents cultivation mode, as well as how to realize the integration of accounting discipline and other disciplines, establish higher vocational colleges, applied universities and research-oriented universities in the current status of colleges and universities.

Although the quantity of articles on the research of artificial intelligence in accounting field published in recent two years is increased obviously, the research is still in the initial stage; the research is independent and separated; and relevant theories and practical experiences are still not mature. The reform of accounting education and the transformation, cultivation and improvement of accounting talents both need to be guaranteed by policies and systems. Therefore, in the future, it is possible to explore the development of international artificial intelligence in accounting field, learn from its successful experience and practice in specific industries and fields in China to further drive the improvement of relevant policies and systems, the innovation of organizational methods, and the improvement of accounting personnel training and explore a way to realize artificial intelligence based accounting with Chinese characteristics.

\section{REFERENCES}

[1] Han Xiaofang, Liu Bingjie. Constraints and Countermeasures of Accountant Training in the Age of Artificial Intelligence [J]. Journal of Lianyungang Teachers College, 2019, 36(02): 92-95. (in Chinese)

[2] Wu Xiaofen, Tian Haiyang. A Comparative Study of Chinese and Foreign Artificial Intelligence Audit Research Hotspots and Evolution Knowledge Maps [J]. Science and Technology Management Research, 2019, 39(10): 185-191. (in Chinese)

[3] Liu Jie, Liao Jie, Dong Haiyun. Artificial Intelligence and Auditing Change [J]. Communication of Finance and Accounting, 2019 (13): 19-25. (in Chinese)

[4] Zhang Jun. Research on Accounting Professional Reform in Higher Vocational Colleges from the Vision of "Internet + " Artificial Intelligence $[\mathrm{J}]$. Chinese Vocational and Technical Education, 2019(11): 58-63. (in Chinese)

[5] Peng Qifa, Wang Huiqiu, Wang Haibing. Research on the Risks and Countermeasures of Accounting Artificial Intelligence [J]. Friends of Accounting, 2019(05): 114-119. (in Chinese)

[6] Zhang Yuan, Liu Hai, Li Zhongao. Innovative education's demand for artificial intelligence quotient under the "smart finance" — Taking the case study of data analysis as an example[J]. Finance and Accounting Monthly, 2018(24):98- 104. (in Chinese)

[7] Tang Ying. Discussion on the Transformation of Enterprise Financial Management in the Age of Artificial Intelligence[J]. Finance \& Accounting, 2018(23): 69. (in Chinese)

[8] Qi Beibei. Analysis of Financial Robot Process Automation from Artificial Intelligence Perspective [J]. Finance \& Accounting, 2018(17): 58-59. (in Chinese)

[9] Wang Ying. The change of accounting education in the era of artificial intelligence [J]. Science \& Technology Ecnony Market, 2018 (04): 167-169. (in Chinese)

[10] Wang Jiacan, Su Yang. Artificial Intelligence and Accounting Model Reform [J]. Communication of Finance and Accounting, 2017 (22): 41-43. (in Chinese)

[11] Chen Tingwei. Analysis of the Application of Artificial Intelligence in Accounting Field - Taking Deloitte Financial Robot as an Example[J]. Commercial Accounting, 2018(10):77-78. (in Chinese)

[12] Zhou Yuanyuan, Jia Xiaobo. Application of Artificial Intelligence in Financial Business Integration[J]. Finance and Accounting Monthly, 2007(31): 60-62. (in Chinese)

[13] Li Xiujuan, Chen Yuanyi. Research on the Demand and Training Path of Accounting Talents under the Background of Artificial Intelligence[J]. Journal of Jilin TV \& Radio University, 2018(05): 91 92. (in Chinese)

[14] Liang Ronghua, Shi Jijian. The Application of AI in Finance Decision Supporting System[J]. Computer Engineering and Applications, 2001(08): 118-121. (in Chinese)

[15] Feng Jing. Research on Artificial Intelligence Financial Decision Supporting System[J]. Shanghai Accounting, 1999(04): 39-41. (in Chinese)

[16] Deng Wenwei. A Summary of Accounting Research in the Age of Artificial Intelligence $[\mathrm{J}]$. Finance and Accounting for International Commerce, 2018 (05): 86-88. (in Chinese)

[17] Zhou Yaoling, Fang Ying, Tang Yike. Analysis of the irreplaceability of accounting personnel under the development of artificial intelligence [J]. China market, 2018 (11): 98+102. (in Chinese)

[18] Bai Yuanyuan. Analysis of the impact and transformation of artificial intelligence on financial personnel [J]. China Township Enterprises Accounting, 2018 (04): 257-258. (in Chinese)

[19] Chen Minjie. The impact of artificial intelligence shock on basic accounting practitioners [J]. Modern Enterprise, 2018 (04): 82-83. (in Chinese)

[20] Wu Weixia. The impact of artificial intelligence on audit work [J]. Chinese Foreign Entrepreneurs, 2018 (10): 155 + 159. (in Chinese)

[21] Zhang Yiyou. On the application of artificial intelligence in enterprise financial management [J]. China Journal of Commerce, 2018 (06): 16-17. (in Chinese) 
[22] Chen Hong. Analysis of the application of artificial intelligence in accounting management [J]. Knowledge Economy, 2018 (02): $108+$ 110. (in Chinese)

[23] Lei Liping. Analysis of the impact of artificial intelligence on the accounting industry [J]. Accountant, 2017 (21): 7-8. (in Chinese)

[24] Huang Liaolong. A Brief Discussion on the Application of Artificial Intelligence Technology in Financial Management[J]. Coastal Enterprises and Science \& Technology, 2009(12): 47-51. (in Chinese)

[25] Wang Jing. Research on Application of Artificial Intelligence in University Financial Service - Taking the University of Electronic Science and Technology of China as an Example [J]. Studies of Finance and Accounting in Education, 2017, 28(06): 76-80. (in Chinese)

[26] Huang Liucang. The Challenge and Response of Artificial Intelligence Development to Accounting Work[J]. Studies of Finance and Accounting in Education, 2017, 28(02): 3-8. (in Chinese)

[27] Wang Shijing. Thoughts on the Cultivation of Higher Vocational Accounting Talents under the Background of Artificial Intelligence[J]. China Township Enterprises Accounting, 2019(06):290-291. (in Chinese)

[28] Chen Xiaoqin. Accounting Talents Training Mode in the Age of Artificial Intelligence[J]. Commercial Accounting, 2019(09): 127-129. (in Chinese)

[29] Lu Nan, Lu Yajun. Research on the "Four in One" Accounting Talents Training Model under the Background of Artificial Intelligence[J]. Commercial Accounting, 2019(08): 110-113. (in Chinese)

[30] Liu Kailin, Xu Tong, Zhang Wanshu Wei, Zhang Xiaodan. Innovation and Reform of Accounting Talents Training Mode in Colleges and Universities under the Trend of Artificial Intelligence [J]. Modern Information Technology, 2019, 3(07): 172-174. (in Chinese)

[31] Peng Chafang. Challenges and Countermeasures of Accounting Talents Training in Artificial Intelligence Environment [J]. Modern Enterprise, 2019 (03): 20-21. (in Chinese)

[32] Su Xiao, Dai Yixiang. Practice of innovative management accounting talent training mode under artificial intelligence and big data environment [J]. Commercial Accounting, 2019 (03): 116-118. (in Chinese)

[33] Qi Dianwei. The Transformation and Reconstruction of Accounting Talents Training Mode under the Background of Artificial Intelligence - Taking Changchun University of Science and Technology as an Example[J]. Commercial Accounting, 2018(16):122-124. (in Chinese)

[34] Shang Sizheng, Chen Jianyun, Dai Huajiang, Luo Yang. Discussion on the Status of Finance and Accounting Courses in Accounting Major of Applied Colleges and Universities in the Age of Accounting Robotics[J]. Finance and Accounting Monthly, 2018(05):132-136. (in Chinese)

[35] Sun Hongxi. Discussion on the service mode of financial sharing center in the era of big data [J]. China International Business (English and Chinese), 2017 (19): 210-211. (in Chinese)

[36] Zuo Zhanwei. Research on Strengthening the Cultivation of Management Accounting Talents [J]. Commercial Accounting, 2016(03): 107-109. (in Chinese)

[37] Xu Yingjie, Gu Linlin, Deng Jinpeng. Application of artificial intelligence to detecting fraud accounting[J]. Journal of Shenyang University of Technology, 2005(02):223-225. (in Chinese) 